ISSN 1991- 8690

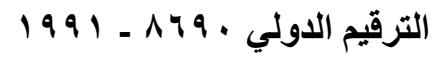

Website: http://jsci.utq.edu.iq

Email: utjsci@utq.edu.iq

دراسة تاثير مطروحات المخلفات النفطية في بعض الصفات الفسلجية لنباتي البردي والقصب

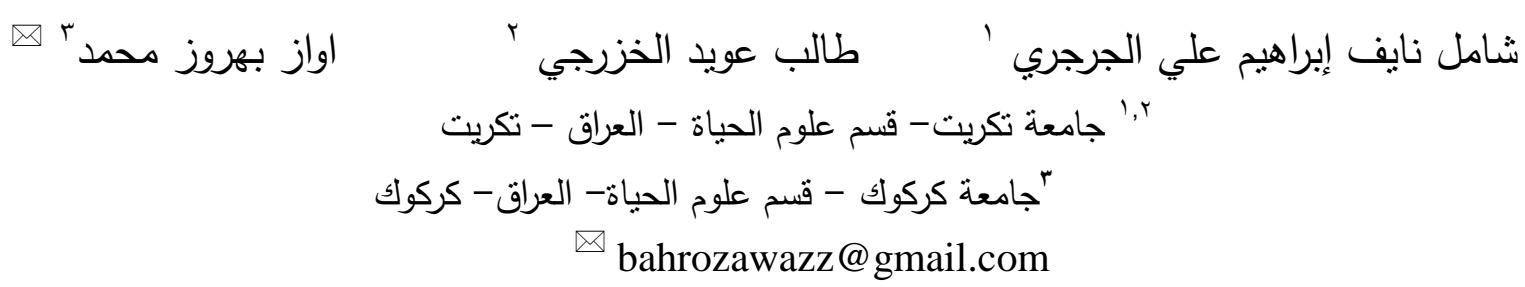

الخلاصة:

تمت دراسة بعض العناصر الثقبلة في نباتات سائدة في مواقع مختارة لمطروحات شركة مصافي الثمال في بيجي/ صلاح الدين وكذلك دراسة

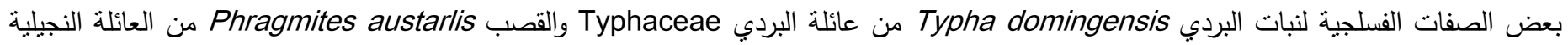

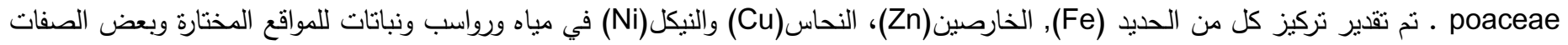

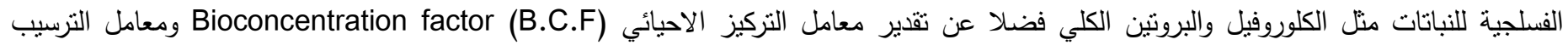

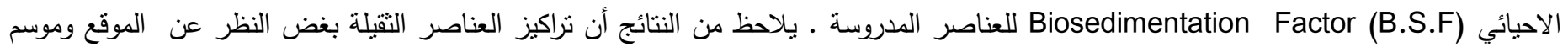
النمو نركزت في المجموع الجذري لنبات البردي لكل من الحديد والزنك أكثر مما للمجموع الخضري. ويلاحظ أيضاً أن الحديد كان أكثر نركزاً في نبات البردي والنحاس في نبات البردي والزنك في القصب يليه البردي والنيكل في نبات القصب. وند وند من نتائج الدراسة أن قيمة معامل التركيز الإحيائي للعناصر

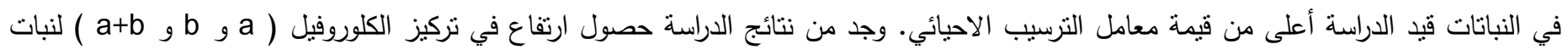

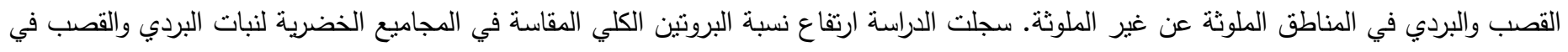
المواقع عن السيطرة. الكلمات الدالة : العناصر النقيلة ، المخلفات النفطية، النباتات المائية، الماء، الراسب

\title{
Study the effect of matarouhat oil residue in some physiological characteristics of Typha domingensis and Phragmites australis
}

\section{$\underline{\text { Abstract }}$}

Some heavy metals were study in prevalent in palns dominated in selected sites in North Refineries Company in Baiji / Salah Al-Din, as well as the study of some physiological characteristics of Typha domingensis and Phragmites austarlis. The concentration of each of the, $\mathrm{Ni}, \mathrm{Cu}, \mathrm{Zn}, \mathrm{Fe}$ in water, sediment, plants for selected sites as well as some physiological characteristics of plants such as chlorophyll, total protein were determined. Also the $\mathrm{BCF}$ bioconcentration factor $(\mathrm{BCF})$ and The results indicated that the concentrations of heavy metals regardless of sites and season of growth were more concentrated in the root of the plants both iron and zinc than in shoot. It is also noted that the iron was more concentrated in the T. domingensis and Phragmites austarlis and copper and zinc in the $T$. domingensis .Results of the study found that the value of the bio-concentration factor of the elements in plants under study higher than the value of the sedimentation factor. The results of the study indicated the increase in the 
concentration of chlorophyll $(\mathrm{a}, \mathrm{b}$ and $\mathrm{a}+\mathrm{b})$ to plant reeds table (24) and papyrus table (23) in contaminated areas for non-polluting. The study recorded a high percentage of total protein measured in T. domingensis and P. austarlis.

Key wards: Heavy metals, oily waste, aquatic plants, water, sediments

\section{وصف منطقة جمع عينات الاراسة : \\ تمند منطقة الدراسة مسافة (r ا ) كم تقريباً تبدأ:-}

1- الموقع الأول:- يتمنل ببداية القناة المسمى بقناة النوري والتي نطرح

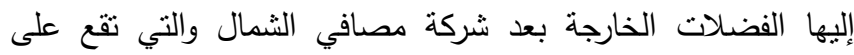
الثناطئ الغربي لنهر دجلة إلى الثمال من مدينة بيجي والني تحوي

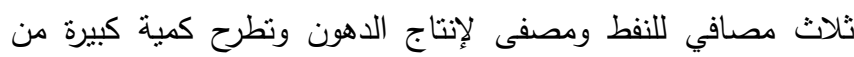
الفضلات وتتقل بوساطة قناة مفتوحة عبر عدد من المناطق الزراعية مما يتيح استخدام مياهها في الزراعة من قبل أهالي تلك القرى وتتميز

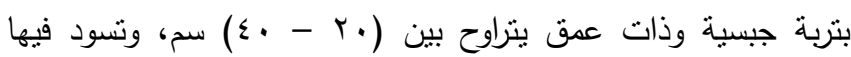
نباتات القصب والبردي. ץ- الموقع الثاني :- يقع في قرية البوجواري والذي يبعد حوالي . .

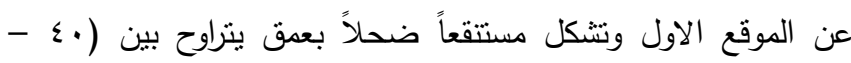

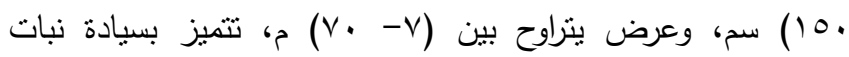

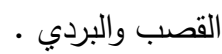

r- الموقع الثالث:- ويقع في حي المهندسين والتي عندها تلتقي المياه الصناعية بمياه نهر دجلة ويسود فيها نبات القصب فقط، وذات نربة

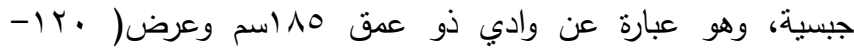

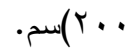
ع- موقع السيطرة :- ويمنل موقع السيطرة بقضاء الثرقاط وقع الاختيار عليها كونها بعيدة عن تأثثر التلوث النفطي من جهة وتنتشابه

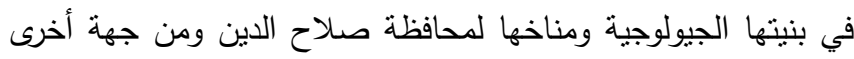
تتواجد فيها النباتات المدروسة، والذي دفعنا إلى اختيار هذه المواقع هو

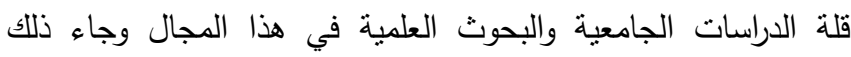

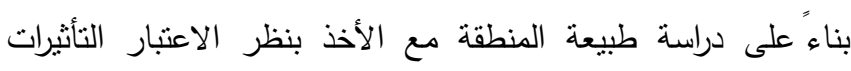
المباشرة للأحياء السكنية والقرى المجاورة المارة بها.

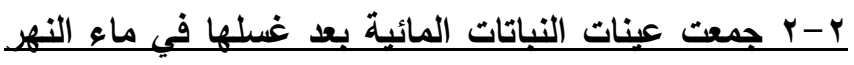
للتخلص من المواد العالقة وتم حفظها في اكباس بلاستبكبة لحين الوصول المى المختبر.

T. domingensis L. Lم جمع العينات لنباتات البردي والقصب .P. australis L. ، وتقدير العناصر النقبلة في المجموع .

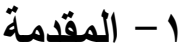

Waste إن إحدى أهم مشاكل التلوث البيئي هي المياه العادمة water

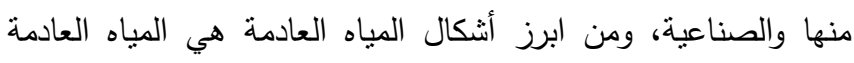
النفطية Oily Wast water الناتجة عن المصافي وعمليات نكرير النفط ومشنقاته، والتي تُطَرحُ إلى المسطحات المائية مؤدية إلى تلوثها (Faris \& Abdel Magid,2003). أجريت دراسات عدة في العالم على النباتات في البيئات الملوثة بالملوثات العضوية واللاعضوية لا لان سيما النباتات المائية الكبيرة aquatic macrophytes التي هي نباتات مائية تتمو في أو قرب الماء اذ قد تكون مغمورة emerged أو أو

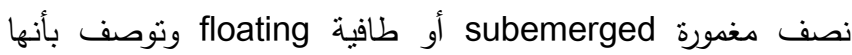
مرشحات بايولوجية biological filters تقوم بإزالة الملوثات من

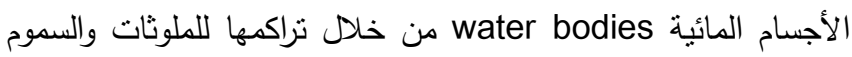
في أنسجتها فضلا عن أنها توفر الغذاء والمأوى للأسماك واللافقريات

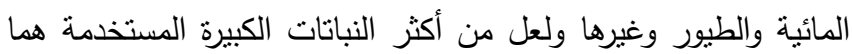

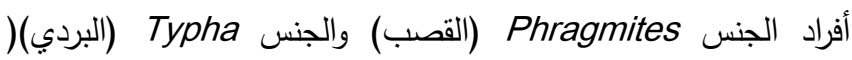
Armstrong g Begum et al. 2009 gaine et al.,2009 Sarma g Hadad et al.,2010 و \& William, 2001

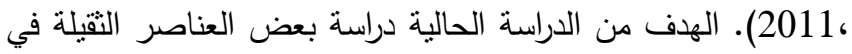

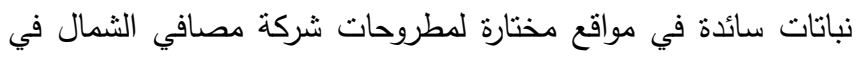
بيجي/ صلاح الدين وكذلك دراسة بعض الصفات الفسلجية لنبات

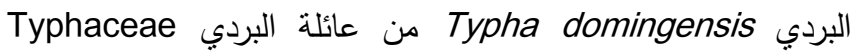
والقصب Phragmites austarlis من العائلة النجيلية poaceae .

r - مواد العمل وطرائقه

r

تقع شركة مصافي الثمال على بعد أربع كيلومترات شمال

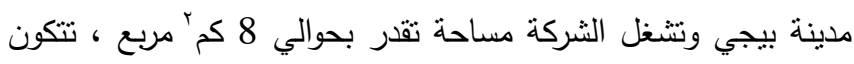
الثركة من أربع مصافي هي :- مصفى الدهون ، مصفى الثمال،

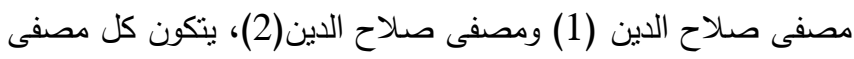
من عدد من الوحدات الإنتاجية. 
تم تقدير البروتين الكلي باستخدام طريقة Kjeldhl methods حسب ما

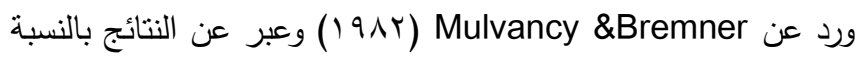

$$
\text { المئوية (\%) : }
$$

البروتين الكلي \% = كمية النتروجين \% 6 \%

r -ه التحليل الإحصائي

استخدم البرنـامج الإحصـائي (SAS(2001)، ولتحديد الفـروق

المعنويـة بين العوامل المدروسـة تم إجراء اختبـار دانكن (Duncan)

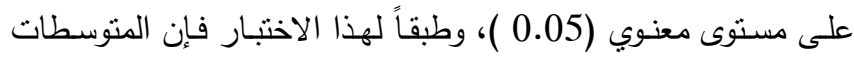

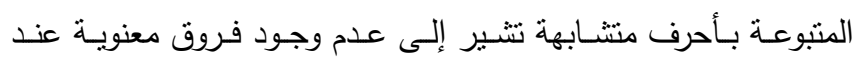

$$
\text { مستوى معنوي (0.05). }
$$

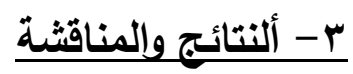

\section{ب-1 العناصر الثقبلة في النباتات المائبة المدروسية}

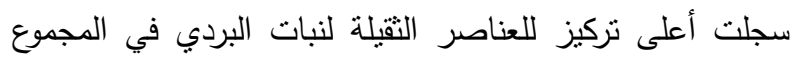

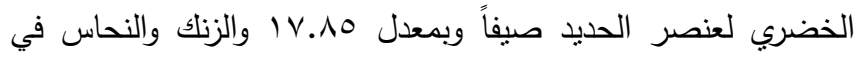

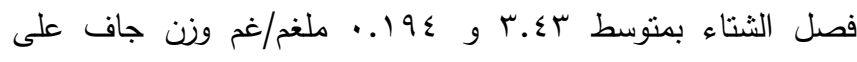

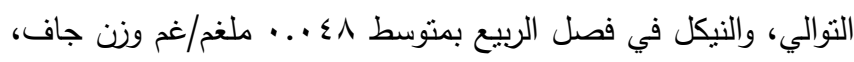

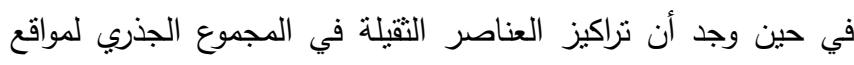

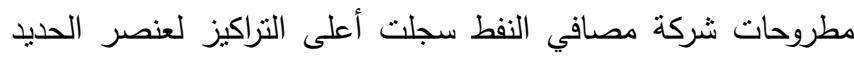

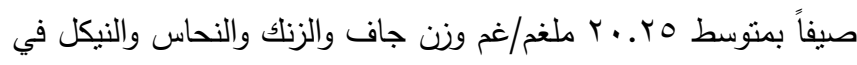

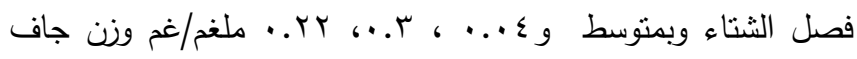

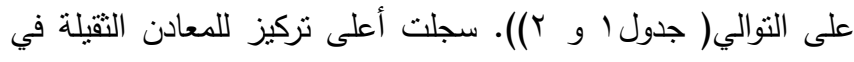

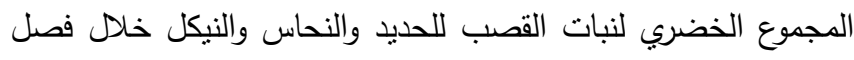

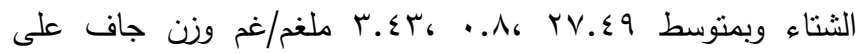

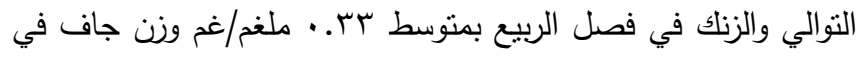
المواقع الواقعة تحت تاثير شركة مصافي الثمال. في حين وجد أن

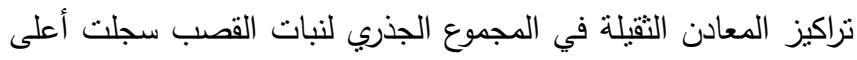

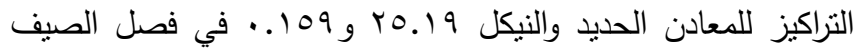

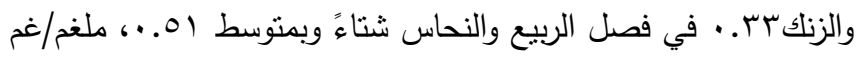
وزن جاف وعلى النوالي. كما يلاحظ من النتائج (جدول ا الو و r) أن

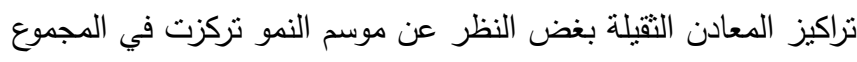

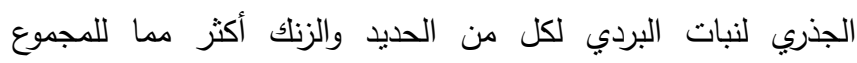
الخضري وسجلت نفس النتائج بالنسبة لنبات القصب فقد إذبد إنثار Hegazy et al., الجذري لنبات البردي T. domingensis ثم تلنها الأوراق القديمة.
الخضري والجذري كما ورد في طريقة (APHA,2003)، وعبر عن

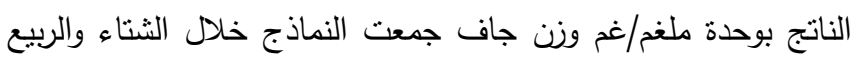

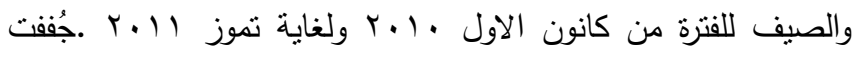

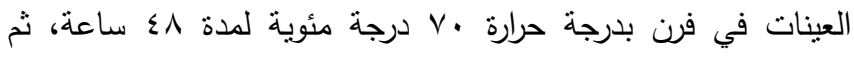

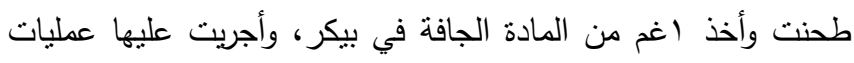

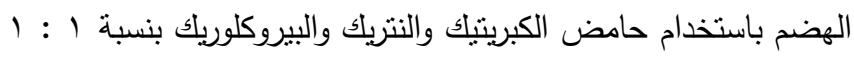

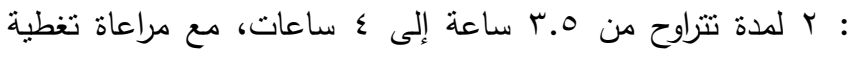

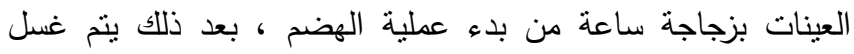

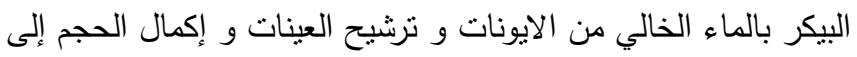

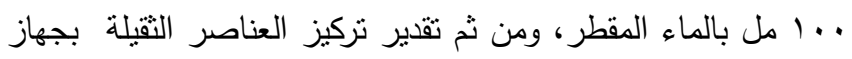

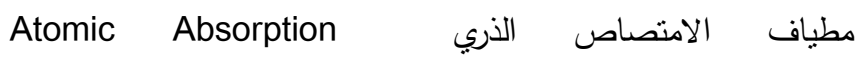
Spectrophotometer خلال المنحنى القياسي لكل عنصر بمكن إيجاد تركيز كل معدن من

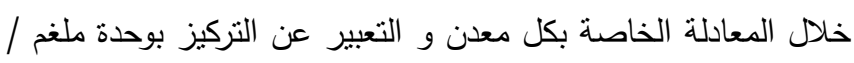
غم وزن جاف.

\section{Bioconcentration factor r-r معامل التركيز الاحيائي}

Biosedimentation ومعامل الترسيب الاحيائي (B.C.F) Factor (B.S.F) حسبت تبعاً لطريقة (Evans \& Engel, 1994) وذلك

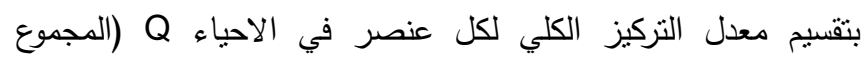
الخضري والجذري)على تركيزه في الماء B والراسب C على التوالي. B.C.F $=\mathrm{Q} / \mathrm{B} \quad$ B.S.F $=\mathrm{Q} / \mathrm{C}$

حيث نم تقدير العناصر الثقيلة في المياه والرواسب باستخدام حامض

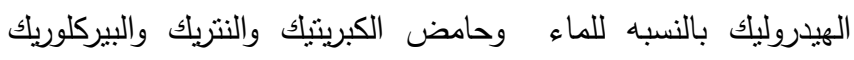
بنسب(r: (: : (1) بالنسبة للراسب

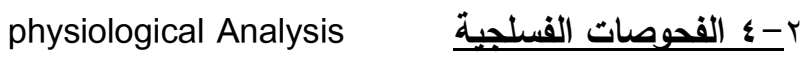
Determination (ملغم/غرام) م- (تقدير الكلوروفيل في الأوراق of Chlorophyll in Plants تم قياس الكلوروفيل حسب طريقة (Arnon Makinny) وكما

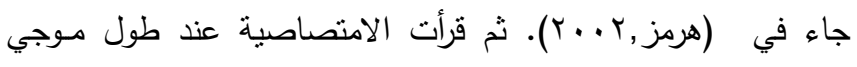

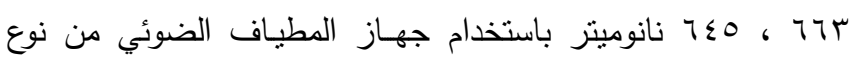
.spectrophotometer/cam Determination of Total protein r- ب- تقدير البروتين الكلي 
ككل ـ أن تراكم العناصر الثقيلة في النباتات يعتمد على نوع النبات ومرحلة نموه، وكذللك على نوع العنصر والية انتقاله إلى أجزاء النبات. r-r معامل الترسيب الإحيائي BSF ومعامل التركيز الإحيائي BCF

حسبت معامل الترسيب الإحيائي BSF ومعامل التركيز الإحيائي BCF بعد تقدير العناصر الثقيلة في الماء والراسب

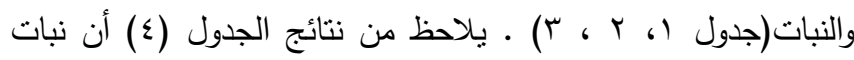
القصب P. australis سجل أعلى معدل لمعامل الترسيب الإحبائي

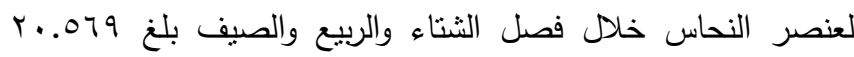
مقارنة بنبات البردي T. domingensis الذي سجل معدلات مرتفعة

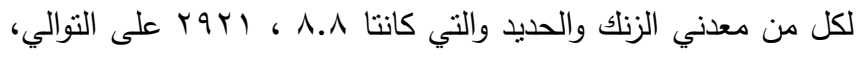

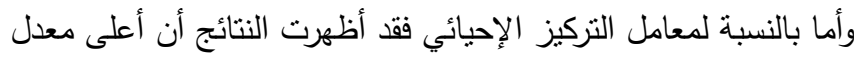

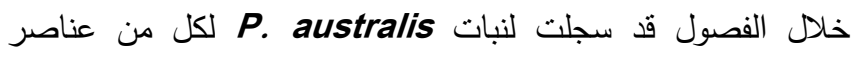

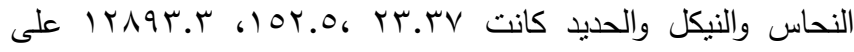
التوالي، أما نبات T. domingensis فسجل أعلى معدل لمعامل التركيز الإحيائي لعنصر الزنك خلال الفصول بلغ 7.7 ب . .. كما وجد

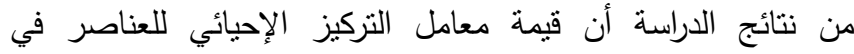
النباتات قيد الدراسة أعلى من قيمة معامل الترسيب الحياتي وسجلت فئل

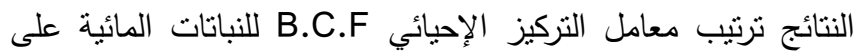

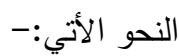

$\mathrm{Fe}>\mathrm{Zn}>\mathrm{Cu}>\mathrm{Ni}: \quad P$. austaralis

$\mathrm{Fe}>\mathrm{Cu}>\mathrm{Zn}>\mathrm{Ni}: \quad$ T. domingensis

أما قيم معامل الترسيب الإحيائي B.S.F فكانت على النحو الأتي:$\mathrm{Fe}>\mathrm{Cu}>\mathrm{Zn}>\mathrm{Ni}: \quad P$. austaralis

\section{$\mathrm{Fe}>\mathrm{Cu}>\mathrm{Zn}>\mathrm{Ni}: \quad$ T. domingensis}

أن الزيادة في معامل التركيز الإحيائي لكل من النحاس والنيكل والحديد

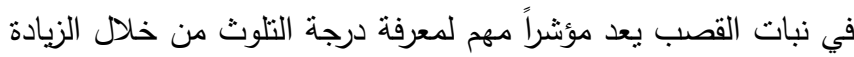
الحاصلة في تركيزها داخل النبات نتيجة زيادة تركيزها في البيئة. تفوقت

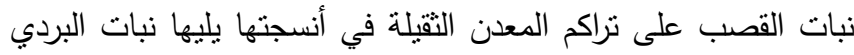
الذي أظهر قدرة على تراكم الحديد والزنك في أنسجتها وعليه نم اعنبار هذه النباتات من المؤشرات الجيدة التي يمكن استخدامها لمعرفة مدى

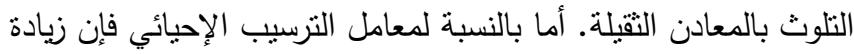

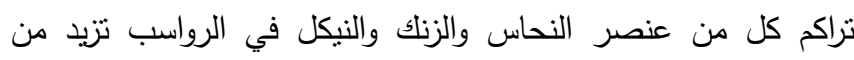

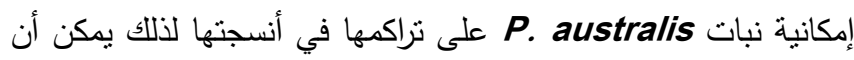
تعد دليلا حيوياً مهماً للكثف عن التلوث من خلال فعالية قدرة النبات

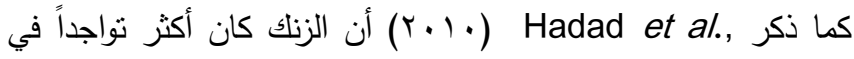
المجموع الجذري عن الخضري لنبات البردي Tomingensis المناطق الملوثة عن غير الملوثة. كما أنشار إلى ذلك أيضاً دراسة ) Ying Manios et al.,2003 Cardwell et al.,2002 (Ma,2005 ; النبات ومرحلة نموه، وكذلك على نوع المعدن والية انتقاله إلى أجزاء النبات المختلفة وحالة التكيف الفسلجي للنبات، ويعتمد أيضا على آلية السبطرة على عملية التراكم المعادن السامة.

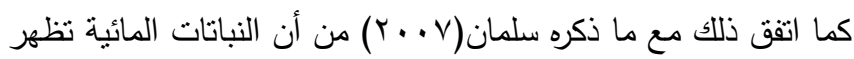

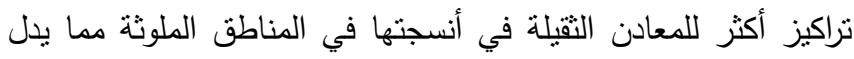

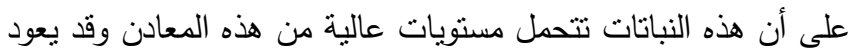

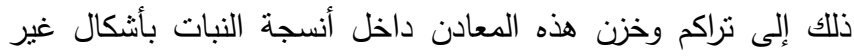

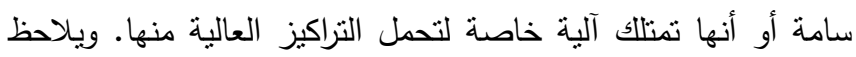

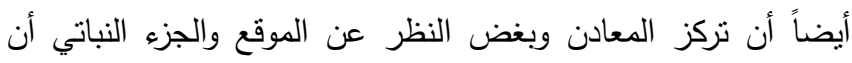
الحديد والنحاس كان أكثر تركزاً في نبات البردي والزنك في القصب وني يليه البردي والنيكل في نبات القصب. وأظهرت الدراسة أيضاً ارتفاع تراكيز المعادن المدروسة في النباتات المائية عما هو عليه في الحالة الذائبة

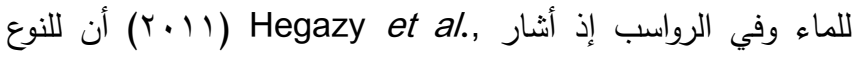
T.domingensis

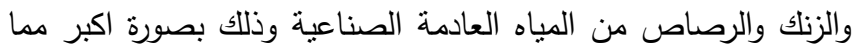
من الرواسب sediments على أن أعلى مسنوى للتراكم كان في مني

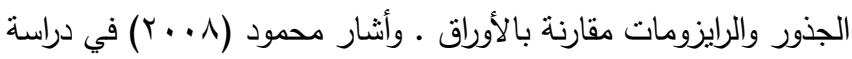
على شط العرب وبعض الأهوار في البصرة إلى أن جميع النباتات

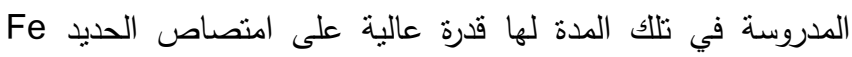

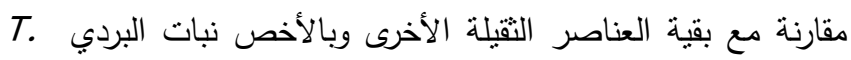
domingensis

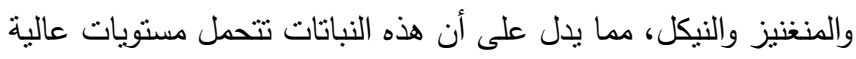

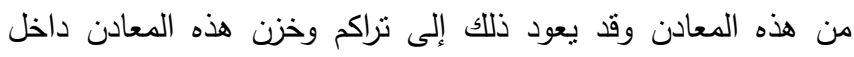

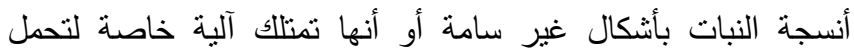
Sarma Memon et al.,2000). التراكيز العالية من المعادن

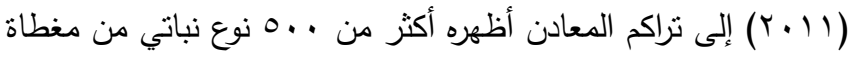

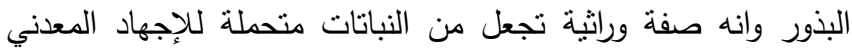
Metal tolerance تكيف النبات للبيئات المعدنية المنطرفة على المستوى التشريحي والنبات 
ع- ارتفاع في تركيز الكلوروفيل a وكلوروفيل b والكلوروفيل الكلي

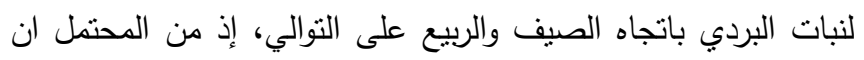

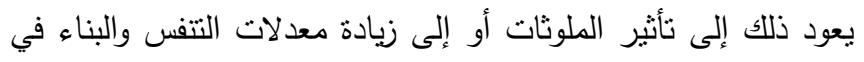

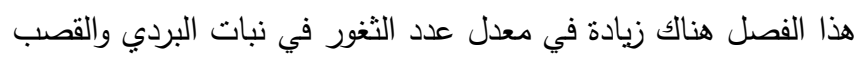

$$
\text { في المناطق الملوثة وفي الفصول الحارة. }
$$

0- ارتفاع في تركيز الكلوروفيل a وكلوروفيل b والكلوروفيل الكلي

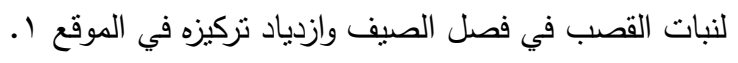

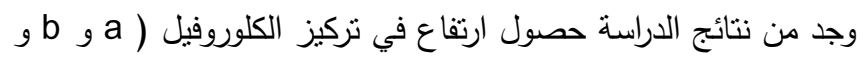

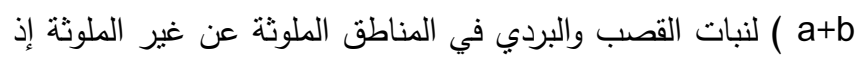
أثنارة دراسات أخرى حول نأثير التلوث النفطي في محتوى الكلوروفيل

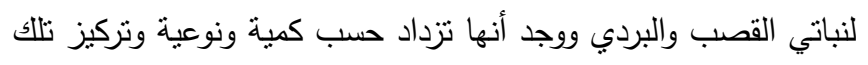

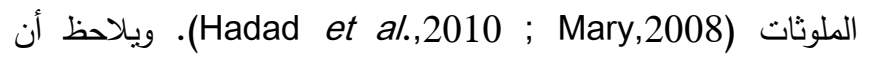
تركيز الكلوروفيل في المناطق الملوثة يكون تحت نأثير الزيادة أو

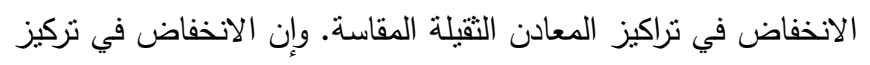

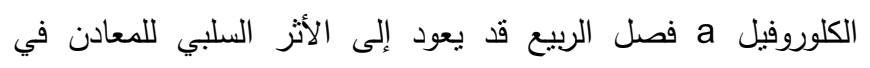

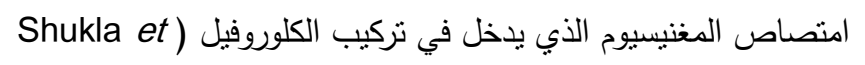
al.,2010) والذي يعود إلى نأثير وجود المعادن إذ تعمل على تلى تثبيط

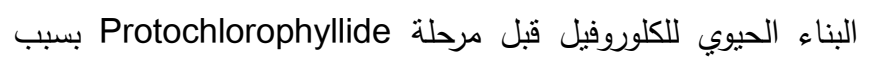

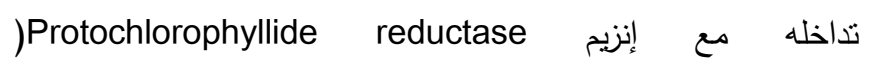
Zengin\&Munzuroglu,2005). كما قد يعود الانخفاض بتركيز

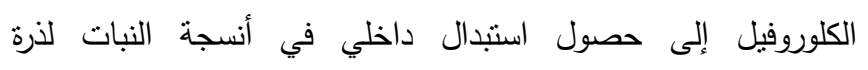
المغنيسيوم الواقعة في مركز جزيئه الكلوروفيل بذرات المعادن النقيلة

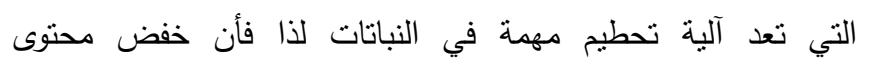

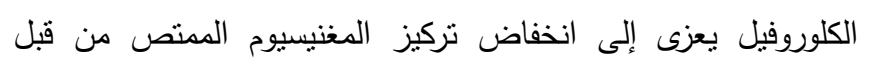

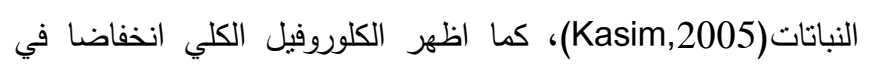

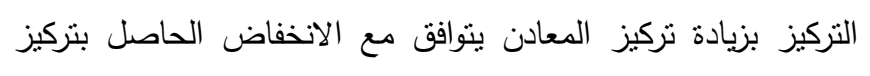

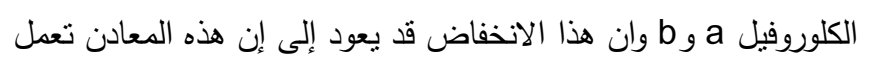

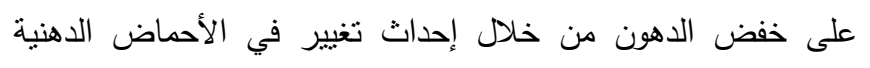
لأغشية الثايلاكويد ونقص في الفعالية الكيميائية للنظام الضونئي الثاني

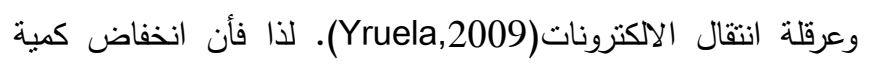

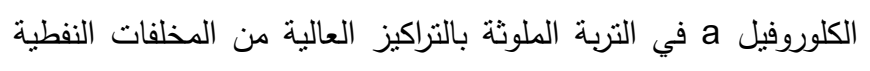

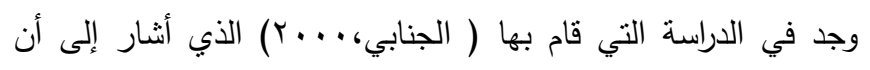

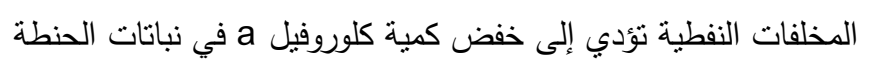

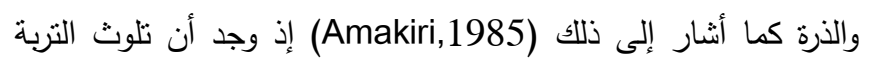

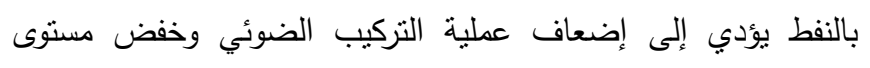

على امتصاص المعادن الثقبلة من الرواسب نتيجة لزيادة جاهزيتها،

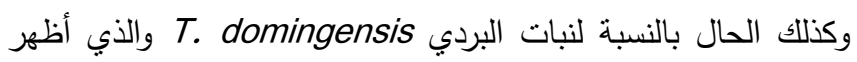

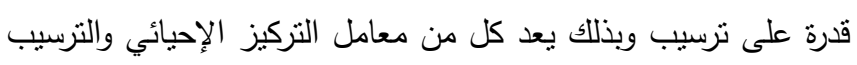

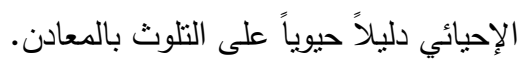

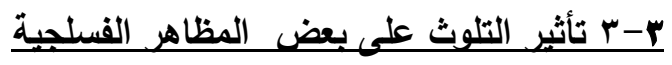

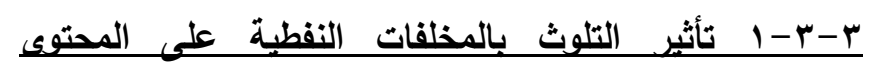
الكلورفيل في أولق النباتات المدروسة في مواقع شركة مصافي الشمال. تعتبر عملية البناء الضوئي من أكثر التفاعلات البايولوجية أهمية

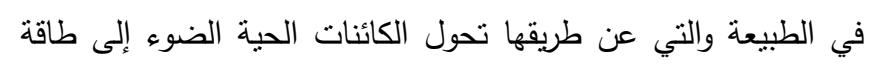

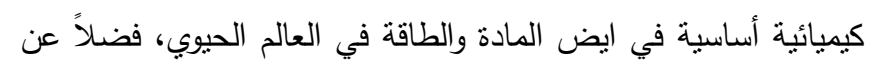

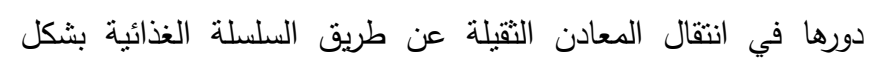

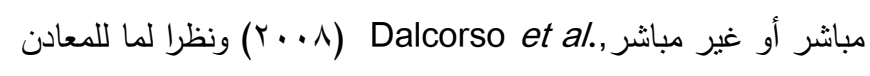

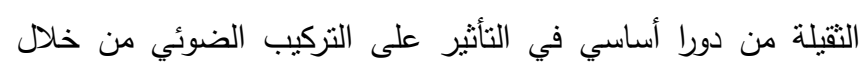

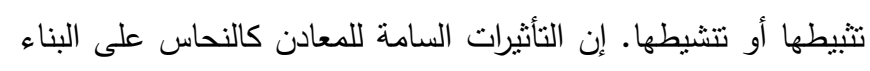

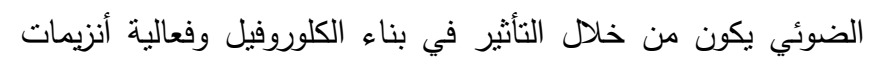
دورة كالفن( Chugh \& Sawhney,1999 ). كما أن التركيز المنخفض لمعدن النحاس يزيد من محتوى الكلوروفيلa بينما التركيز

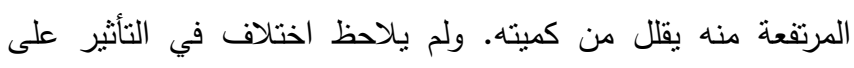

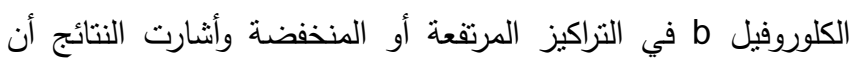
محتوى الكلوروفيل كان اقل نأثر في المناطق الملوثة عن الغير الملوثية إحذاث Li et al.,

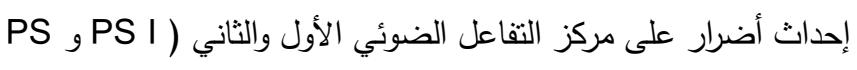

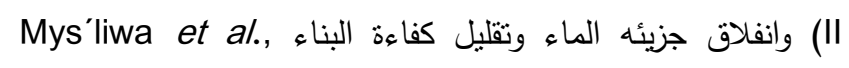

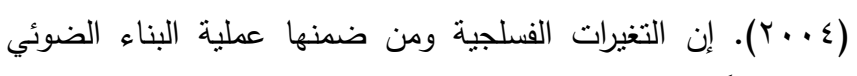
تكون دائماً مترافقة مع التغيرات التي تحصل في البيئة نتيجة الاجهادات

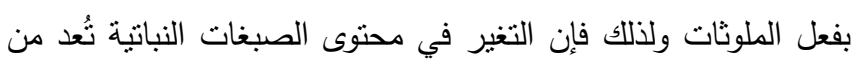

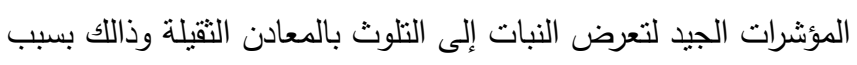

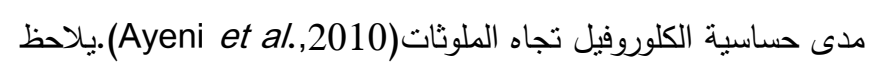
من الجدولان مو 7 ما يلي: مدئي 1- ازدياد في نركيز الكلوروفيلa وكلوروفيلط الكيل والكلوروفيل الكلي لنبات البردي والقصب للمواقع الملوثة عن السيطرة

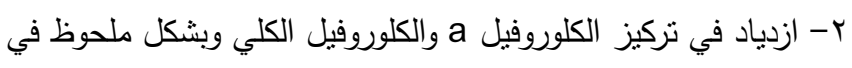

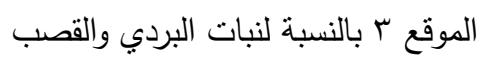


النقيلة ومحتواها من المواد الكيمبائية كالكبريت مقارنة بالمناطق الأخرى الأقل تلوثاً إذ أن وجود المعادن النقيلة بتراكيز عالية تعمل على على حدوث انخفاض في عدد الحزم البروتينية وتسبب إعاقة تصنيع ببتيدات متعددة

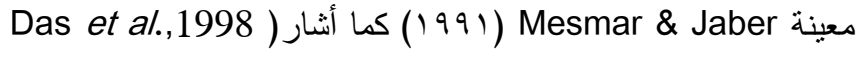
) الذي يرى أن المعادن النقيلة تعمل على خفض معدلات النمو وبالتالي خفض مستويات ATP واختزال عملية بناء البروتينات كذلك نتيجة

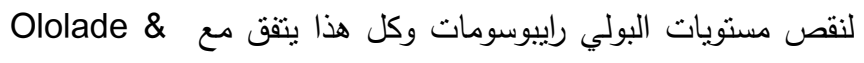
من أن زيادة نركيز المعادن النقيلة تؤثز سلبا على تركيز البروتينات في بعض النباتات. أما بالنسبة للتراكيز العالية من البروتينات فقد ظهرت في المجاميع الخضرية لنبات لنبات فئن النيات القصب ثم البردي .ازداد المحتوى البروتين مع ازدياد تركيز المعادن

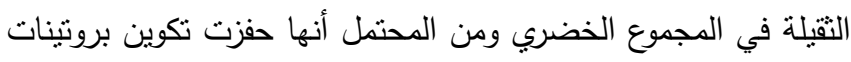
دفاعية إذ لوحظ أن معظم التجارب للكثف عن القلويدات والتانينات

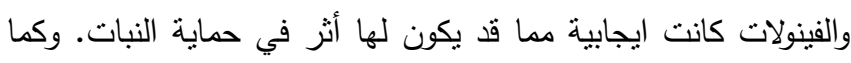

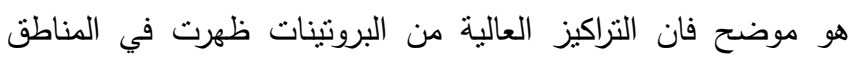
الملوثة عن غير الملوثة وقد يعزى ذلك لوجود المغذيات وتكيف النبات

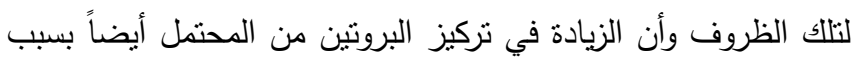

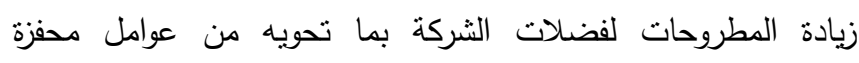

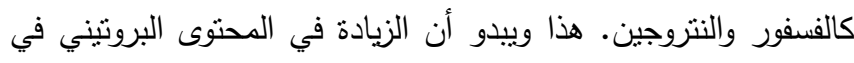

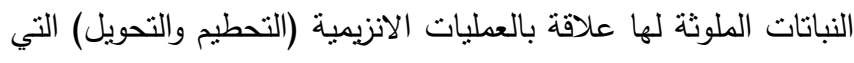

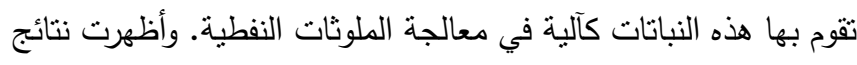

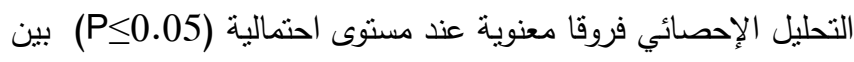
الفصول والمحطات المدروسة عن السبطرة.
الكلوروفيل مع زيادة تركيز النفط في التربة. يعزى انخفاض كمية الكلوروفيل a إلى وجود العناصر النقيلة في المخلفات النفطية المضافة

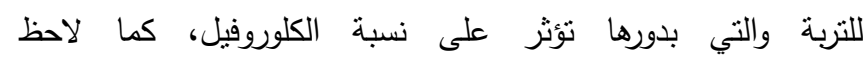
(Vassilev,2003)

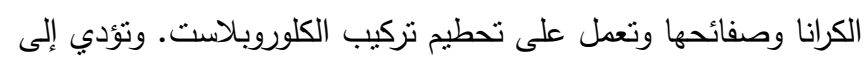
تنيط نمو البلاستيدات الأولية في أوراق نبات الحنطة (

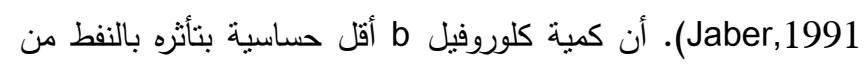

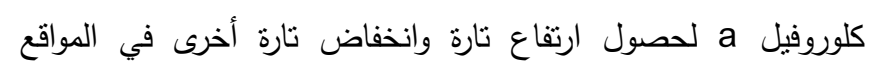

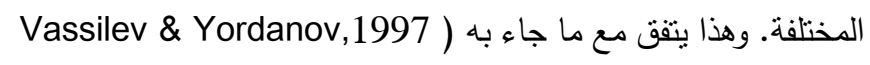
) بأن الكلوروفيل a كان أكثر حساسيةً من كلوروفيل b وذللك لزيادة

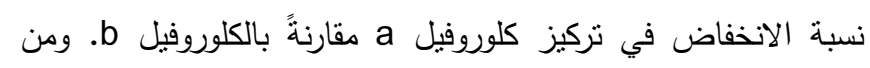

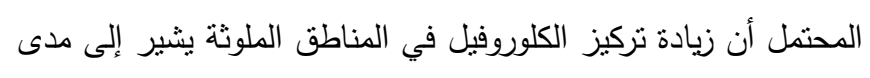

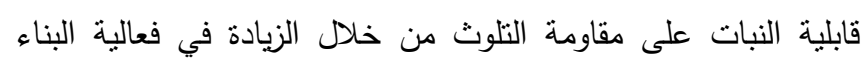

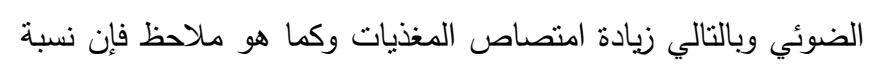

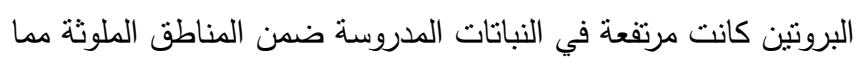

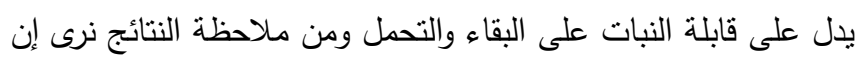
تركيز الكلوروفيل يزداد في فصل الصيف والربيع لما لدرجة الحرارة من فئن

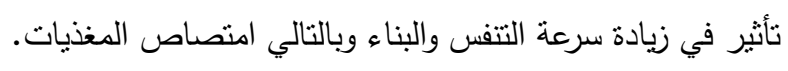

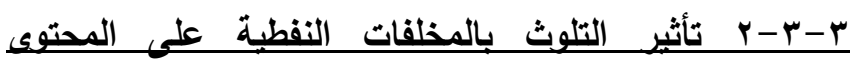
البروتيني في أولق التباتات المدروسة يلاحظ من نتائج الدراسة الحالية أن المحتوى البروتين الكلي

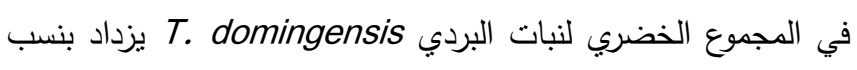

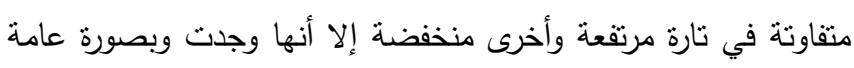

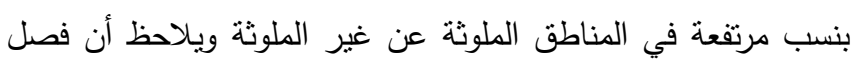

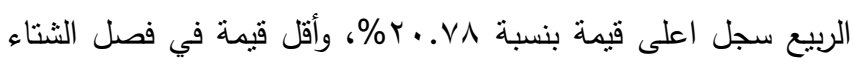

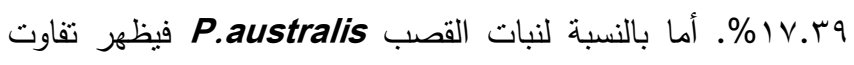

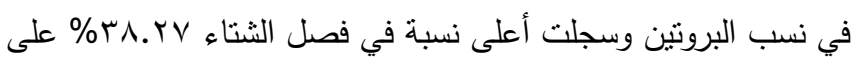

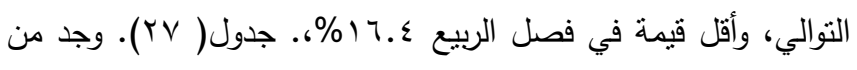
النتائج أن هناك اختلافات معنوية في المحنوى البروتيني في النباتات

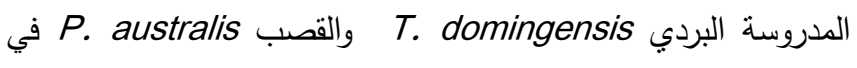
المناطق المدروسة، إذ نرتفع نسبة البروتين الكلي المقاسة في المجاميع البرديع

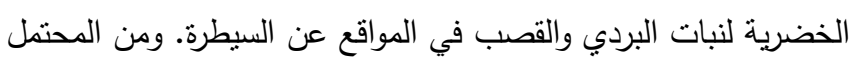

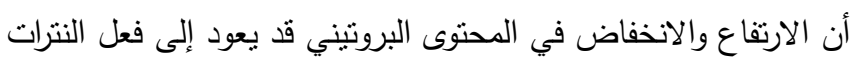

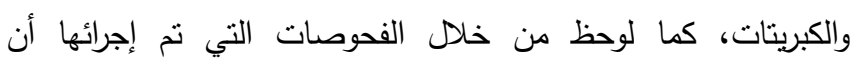
الموقعين الأولى والثاني بالأخص كانت أكثر المواقع تلوثاً بالمعادن 
جدول(r): تركيز المعادن الثقلة في المجموع الخضري والجذري لنبات P. australis

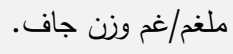

\begin{tabular}{|c|c|c|c|c|c|}
\hline منُوريط مسطناً & صبئ & ريب & سُّاء & & قَبِاس \\
\hline $\begin{array}{ll}114 & 0 \\
11 & 0\end{array}$ & $\begin{array}{ll}1 \times 0.01 & 6 \\
19.9 & 6\end{array}$ & $\begin{array}{ll}0.145 \\
11.11 & 5\end{array}$ & $\begin{array}{ll}r \because 0 & 0 \\
r .4 & 0\end{array}$ & 1 & \multirow{5}{*}{ طب } \\
\hline 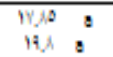 & ros & 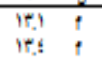 & rotos & $r$ & \\
\hline 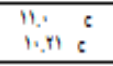 & 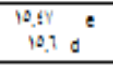 & $\begin{array}{l}\text { ND } \\
\text { ND } \\
\end{array}$ & $\begin{array}{l}1040 \\
0.4\end{array}$ & $r$ & \\
\hline \multirow[t]{2}{*}{$\begin{array}{ll}r 2 y & d \\
r y y & d\end{array}$} & $\begin{array}{ll}! & \mathrm{i} \\
\vdots 0.1 & \mathrm{n}\end{array}$ & $\begin{array}{l}\text { ND } \\
\text { ND }\end{array}$ & $\begin{array}{ll}01,1 & n \\
r i, y & i\end{array}$ & سبطرُ & \\
\hline & $\begin{array}{l}19.0 \% \\
10.19\end{array}$ & 0 & $\begin{array}{ll}N, 49 & 0 \\
r / 4 & 0\end{array}$ & لهدل & \\
\hline $\begin{array}{ll}4 & 0 \\
Y N & 0\end{array}$ & $\begin{array}{cc}0+7 \\
\because 4 \\
4\end{array}$ & $y^{\circ}$ & $\begin{array}{l}\quad 006 \\
\because 09 \mathrm{c}\end{array}$ & 1 & \multirow{5}{*}{ زني } \\
\hline $\begin{array}{ll}41 & 8 \\
41 & 8\end{array}$ & $\begin{array}{ll}\because 0 & 0 \\
\because 1 & 6\end{array}$ & .098 & $\begin{array}{ll}0.018 \\
\because 1 & 8\end{array}$ & $r$ & \\
\hline $\begin{array}{ccc}\because \cdots y & 6 \\
\because+8 & 6\end{array}$ & $\begin{array}{ll}0 \\
\because 11 \\
6\end{array}$ & $\begin{array}{l}\text { ND } \\
\text { ND }\end{array}$ & $\begin{array}{ll}011 & 0 \\
4 & 5\end{array}$ & $r$ & \\
\hline \multirow[t]{2}{*}{$\begin{array}{cc}\cdots \cdot 1 & 6 \\
\cdots & c \\
\end{array}$} & 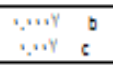 & $\begin{array}{l}\text { ND } \\
\text { ND }\end{array}$ & $\begin{array}{ll}0 . \cdots \pi \\
\cdots\end{array}$ & سبمزرة & \\
\hline & 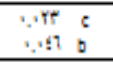 & $\pi$ & $\begin{array}{r}110 \\
\because 10\end{array}$ & لهصل & \\
\hline $\mathrm{N}_{\mathrm{O}}^{\mathrm{C}}$ & $\begin{array}{ll}1 \\
\because 8 \\
6\end{array}$ & $\because 1 c^{6}$ & $\begin{array}{ll}19 & 6 \\
9 & 0\end{array}$ & 1 & \multirow{5}{*}{ ن لداس } \\
\hline : & $\begin{array}{ll}4 & 9 \\
4 & d\end{array}$ & $\begin{array}{l}\because 41 \\
\because 0 \\
6\end{array}$ & 30 & $r$ & \\
\hline \begin{tabular}{ll}
5 & 0 \\
\hdashline & 6
\end{tabular} & $\begin{array}{ll}4 \\
\because 11\end{array}$ & $\begin{array}{l}\text { ND } \\
\text { ND }\end{array}$ & $14:$ & + & \\
\hline \multirow[t]{2}{*}{ 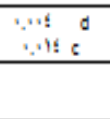 } & $\begin{array}{ll}\cdots & 5 \\
\cdots & 6\end{array}$ & $\begin{array}{l}\mathrm{ND} \\
\mathrm{ND}\end{array}$ & s & سبطرُ & \\
\hline & 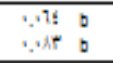 & $\begin{array}{ll}0 & 6 \\
4 & 6\end{array}$ & : 8 & لهدj & \\
\hline $\begin{array}{l}0 ! 48 \\
\because 48\end{array}$ & $\begin{array}{l}.1180 \\
110\end{array}$ & $\because 11 d^{b}$ & $\begin{array}{ll}\because y & b \\
\because 4 & \text { ef }\end{array}$ & 1 & \multirow{5}{*}{ نبكل } \\
\hline 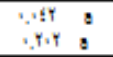 & $\because 110^{\circ}$ & $\begin{array}{ll}\because 1 & b \\
\because V & 6\end{array}$ & $\begin{array}{l}\because 11 \\
\because 4 c^{6}\end{array}$ & $r$ & \\
\hline $\begin{array}{ll}801 & 8 \\
\because 4 & 8\end{array}$ & $\begin{array}{ll} \\
\because 0\end{array}$ & $\begin{array}{l}\text { ND } \\
\text { ND }\end{array}$ & $\begin{array}{l}15.198 \\
108\end{array}$ & + & \\
\hline \multirow[t]{2}{*}{ 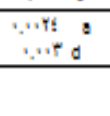 } & 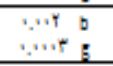 & $\begin{array}{l}\text { ND } \\
\text { ND }\end{array}$ & $\because \cdots 0$ & صبطزرُ & \\
\hline & $\because 198$ & $\because n:$ & 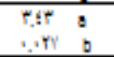 & لهدj & \\
\hline
\end{tabular}

جدول (1): تركيز المعادن الثقبلة في المجموع الخضري(الخط الاول)

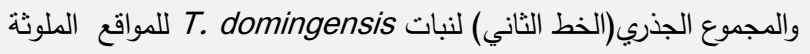
في محافظة صلاح الدين ملغم/غم.

\begin{tabular}{|c|c|c|c|c|c|}
\hline شوبط بطاة & مبـ & تب & 4دار & 帮 & ليبن \\
\hline $\begin{array}{c}11,3 Y^{\prime} \\
\text { W, Y o }\end{array}$ & 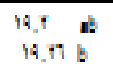 & $\begin{array}{c}118,4 \text { at } \\
0 \%=\end{array}$ & $\begin{array}{l}11,40 \text { at } \\
17,110\end{array}$ & 1 & \multirow{5}{*}{4} \\
\hline $11 \mu_{1,908}$ & 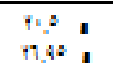 & $\begin{array}{ll}11,14 & \text { at } \\
11,0 & \text { e }\end{array}$ & $\begin{array}{c}1+28 \text { be } \\
\text { its? }\end{array}$ & ' & \\
\hline $\begin{array}{l}\mathrm{ND} \\
\mathrm{ND} \\
\end{array}$ & No & No & No & + & \\
\hline \multirow[t]{2}{*}{$\begin{array}{cc}M, 4 \\
M, 4\end{array}$} & $\begin{array}{cc}+1, Y & 8 \\
+1, & 1 \\
\end{array}$ & $\begin{array}{c}\text { N } \\
\text { No } \\
\end{array}$ & $\begin{array}{r}17,8 \\
+8,1 \\
\end{array}$ & سبطرا & \\
\hline & 19:18, & 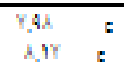 & $\begin{array}{l}10,18 \quad 8 \\
11,108\end{array}$ & Dص & \\
\hline 3040 & $\begin{array}{ll}\because 4 & b \\
\because 4 & 1 \\
\end{array}$ & $\begin{array}{lll}11 & 8 \\
\because 1 & \text { a }\end{array}$ & 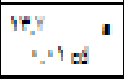 & 1 & \multirow{5}{*}{4} \\
\hline 98 & $\begin{array}{l}\because 4918 \\
\because 411 \mathrm{~d}\end{array}$ & $\begin{array}{ll} \\
\because+11 & b \\
\end{array}$ & $\begin{array}{|cc|}\because 4 & b \\
\because 18 & 8\end{array}$ & ' & \\
\hline $\begin{array}{l}\mathrm{ND} \\
\mathrm{ND} \\
\end{array}$ & $\begin{array}{l}\text { No } \\
\text { No } \\
\end{array}$ & $\begin{array}{l}\text { No } \\
\text { No } \\
\end{array}$ & No & + & \\
\hline \multirow[t]{2}{*}{$\begin{array}{c}4 \% \\
\because 18 \\
4\end{array}$} & $\begin{array}{ll}3+48 \\
\because 48\end{array}$ & " & 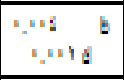 & سيطرا & \\
\hline & $\because+4$ & $\because 4=9$ & $\begin{array}{c}0.84 \\
\because 48\end{array}$ & نصا & \\
\hline $\begin{array}{lll}\because 40 & 0 \\
4 & 0\end{array}$ & $\begin{array}{lll}\because 8 & d \\
\because 4 & d\end{array}$ & $\begin{array}{l}\because 4 \\
\because 4\end{array}$ & $\because 48$ & 1 & \multirow{5}{*}{ 2لين } \\
\hline 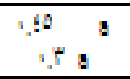 & $\begin{array}{ll}0 \\
\because 4 & 8\end{array}$ & $\begin{array}{ll}\because & b \\
\because 1 & d \\
\end{array}$ & 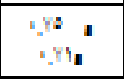 & ' & \\
\hline ND & $\begin{array}{c}\text { ND } \\
\text { no... }\end{array}$ & No & $\begin{array}{|ll|} & 1 \\
& \\
\end{array}$ & + & \\
\hline \multirow[t]{2}{*}{ 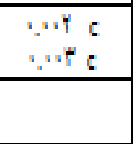 } & $\begin{array}{ll}\because \cdots 4 & d \\
\because \cdots+4 & 1\end{array}$ & No & 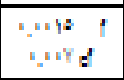 & سبطرا & \\
\hline & 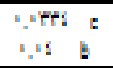 & $\begin{array}{c}0.141 \\
\because+4\end{array}$ & $\begin{array}{c}195 \\
.4 .\end{array}$ & نص & \\
\hline 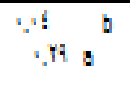 & $\because 11=$ & $\begin{array}{l}844 \\
\because 49=1\end{array}$ & $\begin{array}{l}\because 11 \mathrm{c} \\
\because n\end{array}$ & 1 & \multirow{5}{*}{3} \\
\hline $\begin{array}{ll}\because 04 & 8 \\
\because 48 & 0\end{array}$ & $\begin{array}{l}\because \cdots+4 \\
\because 4 \\
\because 4\end{array}$ & $\begin{array}{lll}\because 49 & 4 \\
\because 14 & 8\end{array}$ & $\because \begin{array}{ll}\because 4 & 8 \\
\because 7 & 8\end{array}$ & ' & \\
\hline ND & $\begin{array}{l}\text { No } \\
\text { No }\end{array}$ & $\begin{array}{l}\text { No } \\
\text { No }\end{array}$ & $\begin{array}{l}\text { No } \\
\text { No }\end{array}$ & + & \\
\hline $\begin{array}{l}3+\cdots 4 \\
\because+46\end{array}$ & $\begin{array}{l}\because \cdots 4 \text { es } \\
\because \cdots s \text { e }\end{array}$ & $\begin{array}{l}\text { No } \\
\text { No }\end{array}$ & $\begin{array}{ll}\because \cdots 1 \text { of } \\
\because \cdots 1\end{array}$ & سيطرا & \\
\hline & 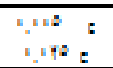 & 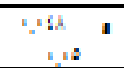 & $\because 18 \quad 8$ & ven & \\
\hline
\end{tabular}


T. جدول (0) : معدل تركيز الكلوروفيل في لنبات البردي

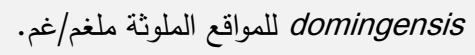

\begin{tabular}{|c|c|c|c|c|c|}
\hline منرويط مسطاك & صبيت & ريبع & ستكاء & & لثباس \\
\hline 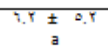 & $\begin{aligned} r, y \\
f \\
f\end{aligned}$ & $\begin{array}{c}Y_{Y} \pm Y, A \\
a\end{array}$ & $\begin{array}{l}Y .1 \pm \cdot A Y \\
c\end{array}$ & , & \multirow{4}{*}{$\mathrm{Chl}=$} \\
\hline $0.1 \pm 6.1$ & 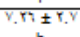 & $\sin \pm 1, y$ & $T, w=1,0$ & $r$ & \\
\hline$T . T+1.6$ & $0, r y+r .4$ & $\begin{array}{l}\text { N } \\
\text { ND }\end{array}$ & $r ., t \pm \cdot . v$ & سبطزرُ & \\
\hline & $\begin{array}{c}4, v \pm x, q \\
a\end{array}$ & $\begin{array}{c}r .9 \pm 1.9 \\
c\end{array}$ & $T \cdot{ }_{B}^{ \pm+A v}$ & لهבנ & \\
\hline$\Gamma_{a}= \pm 1, \Lambda$ & $\begin{array}{c}r .98 \pm r .1 \\
b\end{array}$ & $\begin{array}{r}Y . Y \pm 1, Y \\
d\end{array}$ & $8.80 \pm \mathrm{T} .0$ & , & \multirow{4}{*}{$\mathrm{Chl} \mathrm{b}$} \\
\hline$r, T b_{b}^{ \pm \ldots, V}$ & $\begin{array}{l}\text { T.1: } 1: 0 \\
c\end{array}$ & $\widehat{A}_{f}^{ \pm+\Lambda}$ & $r_{E} \pm 1.0$ & $T$ & \\
\hline 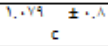 & 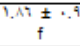 & $\begin{array}{c}\text { NDD } \\
\mathrm{h}\end{array}$ & ${ }_{G}^{1 . T \pm}$ & سبخزرة & \\
\hline & $\begin{array}{c}r, 19 \pm+1 \\
a\end{array}$ & $\begin{array}{c}1 \pm \ldots, k \\
c\end{array}$ & $\begin{array}{c}1.9 \pm+1 \\
B\end{array}$ & انمعل & \\
\hline $9,76 \pm 0.6$ & 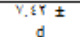 & $9.9 \pm 0.1$ & $11.0 \pm+.9$ & , & \multirow{4}{*}{$\mathrm{Chl}=8 \mathrm{Lt}$} \\
\hline$v_{0.8 t} \pm 1.1$ & $\begin{array}{l}1+\varepsilon_{b} \pm r . y \\
b\end{array}$ & $9,4 \pm r .8$ & $0,0 \pm r, 1$ & $r$ & \\
\hline$\because \pm 9$ & $\frac{7.1 \cdot \pm 8.1}{10}$ & Nd & $7.9 \pm 1.1$ & سبخرة & \\
\hline & $7 . r \pi \pm r .1$ & $f \pm 1, A$ & $0 . Y \pm Y . Y$ & أمعلز & \\
\hline
\end{tabular}

جدول(؟): تركيز الكلوروفيل لنبات P. australis للمواقع الملوثة في المواقع المختارة(ملغم/غم).

\begin{tabular}{|c|c|c|c|c|c|c|}
\hline مستسط محطاك & صبث & 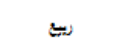 & لنتئه & المبوتي النصن & & \\
\hline 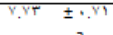 & $1 . Y Y \quad \pm \ldots 0$ & $0, r_{1} \quad \pm \cdots$, & $\bar{Y} \quad \pm \cdots+\cdots$ & , & \multirow{5}{*}{ Chl a } & \multirow{15}{*}{ الدين } \\
\hline 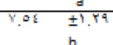 & 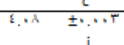 & $\begin{array}{ll}\mathrm{g} \\
1 \times, ., 9\end{array}$ & $0.9 r \quad \pm \cdots$ & $r$ & & \\
\hline $\begin{array}{ll}7.89 & \pm 1.91\end{array}$ & $1+., \quad \pm 0 ., 4$ & $\cdot$ & $\pm \cdots \cdot 9$ & $*$ & & \\
\hline 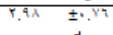 & $0.1 \% \quad \pm \cdots, \ldots r$ & \pm & $\pm \ldots r$ & بهرزً & & \\
\hline & R.,Y $\pm 1,1 T$ & $\varepsilon, 8 Y \quad \pm 1.07 \mathrm{c}$ & $0.4 r \quad \pm . .81$ & المعل & & \\
\hline $8.01 \quad \pm ., Y$ & $r .14 \quad \pm \ldots{ }^{\circ}$ & $0 .+\lambda \quad \pm \cdots$ & 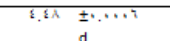 & , & \multirow{5}{*}{ Chl b } & \\
\hline $0.9 \gamma \quad \pm 1 . Y 1$ & $1,+R \quad \pm \ldots . . .0$ & $18.90 \pm . .9$ & 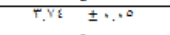 & 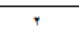 & & \\
\hline $\begin{array}{ll}Y, \lambda & \pm ., Y T \\
c & c\end{array}$ & $8.9 r \quad \pm \cdots \cdot 9$ & ND & $\bar{f} \underset{f}{ \pm \cdots, \cdots 0}$ & ${ }^{*}$ & & \\
\hline $1.10 \quad \pm 0.74$ & $1, \lambda \varepsilon \quad \pm \because .0$ & ND & $n^{ \pm \cdots \cdot .6}$ & سبنرة & & \\
\hline & $\gamma .40 \pm . .8 T$ & $8.0 . \quad \pm 1.04$ & $T . T T \quad \pm ., T 1$ & المعلز & & \\
\hline Tr.YE $\quad \pm 0.8$ & $1+, 19 \quad \pm \ldots, \cdots 9$ & $1.18 \quad \pm \cdots$ & $17.19 \quad \pm \ldots . . . T$ & , & \multirow{5}{*}{$\mathrm{Chl}$ a\&b } & \\
\hline 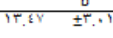 & $0.8 \times \quad \pm \cdots \cdots$ & ro.YA $\quad \pm \because . .0$ & 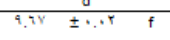 & 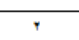 & & \\
\hline $\begin{array}{ll}, Y . & \pm Y ., 7 Y\end{array}$ & $1,19 \pm \ldots \ldots$ & ND & $4, y= \pm \cdots$ & $r$ & & \\
\hline $8.18 \quad \pm 1.00$ & $7.97 \quad \pm \cdots . .7$ & ND & $\begin{array}{ll}0.8 Y & \pm 0 ., \tau\end{array}$ & 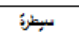 & & \\
\hline & $11.1 \% \quad \pm 1.00$ & $\begin{array}{ll}0.4 \lambda & \pm r .1 r\end{array}$ &., $\pm Y r$ & أمعل & & \\
\hline
\end{tabular}

جدول(V): نسبة البروتين الكلي(\%) في المجموع الخضري لنبات

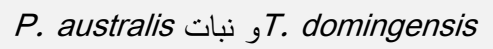

\begin{tabular}{|c|c|c|c|c|}
\hline شئوسط محطاك & عبث & رييغ & لُّتَاء & الهمئع \\
\hline $\begin{array}{l}r r \pm \lambda .9 \mathrm{a} \\
r r .9 Y \pm r . r \mathrm{~b}\end{array}$ & $\begin{array}{l}\text { ro } \pm 1.1 r_{b} \\
19, \pm \pm . r_{f}\end{array}$ & $\begin{array}{l}T_{0} \pm 16.4 \mathrm{~b} \\
\therefore 9 \lambda \pm \cdots \cdot 1 \mathrm{~cd}\end{array}$ & 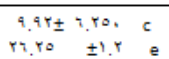 & , \\
\hline $\begin{array}{l}r q \pm 8,1 b \\
\therefore, 1 \pm r .0 \mathrm{a}\end{array}$ & $\begin{array}{l}19.4 \mathrm{Y} \pm 9.0 \mathrm{~d} \\
T Y .1 \mathrm{x} \pm .0 \mathrm{c}\end{array}$ & $\begin{array}{l}2 ., 1 r \pm 10.8 \mathrm{a} \\
r ., i r \pm \mathrm{r} .0 \mathrm{de}\end{array}$ & $\begin{array}{l}r 1, i x \pm 9 . y d \\
\text { or. } 0 \pm 4.0 \mathrm{a}\end{array}$ & $r$ \\
\hline $\begin{array}{c}\mathrm{ND} \\
\mathrm{M}, 1 \pm \varepsilon, \mathrm{r}_{\mathrm{C}}\end{array}$ & $\begin{array}{c}\mathrm{ND} \\
\mathrm{r} \cdot \mathrm{IT}_{ \pm ., \mathrm{r}_{\mathrm{f}}}\end{array}$ & $\begin{array}{l}\text { ND } \\
\text { ND }\end{array}$ & $\begin{array}{c}N D \\
r, Y q \pm \therefore \mathrm{e}\end{array}$ & $*$ \\
\hline 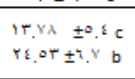 & 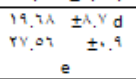 & $\begin{array}{l}\mathrm{ND} \\
\mathrm{ND}\end{array}$ & 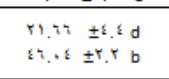 & سبطرك \\
\hline & $\begin{array}{l}18.09 \pm 1.1 \mathrm{~b} \\
r .18 \pm r .10 \mathrm{~b}\end{array}$ & $\begin{array}{c}r, Y A \pm 0.0 a \\
i n \pm 0 . r c\end{array}$ & 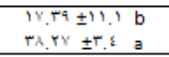 & 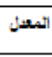 \\
\hline
\end{tabular}

جدول(ץ): تركيز العناصر الثقيلة في المياه(الخط الاول) والرواسب(الخط

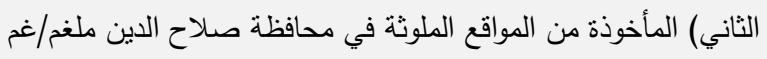
وزن جاف

\begin{tabular}{|c|c|c|c|c|c|}
\hline منَوسط سحطات & مبث & يب & $85^{2}$ & tai & \\
\hline $\begin{array}{c}\because \mathrm{YYA} \\
\because .4\end{array}$ & $\begin{array}{l}\because 4 \\
\because .87\end{array}$ & $\begin{array}{l}r .7 \cdots \\
\because 74\end{array}$ & $\begin{array}{l}\because 10 \\
\because 81\end{array}$ & 7 & \multirow{5}{*}{ طب } \\
\hline $\begin{array}{l}\because \times 1 \\
\because, 4 \lambda\end{array}$ & $\begin{array}{l}\pi T \\
\therefore .07\end{array}$ & $\begin{array}{l}\because \mathrm{TA} \\
{ }^{\mathrm{T}}\end{array}$ & $\begin{array}{l}\because \% \\
\because 0 y\end{array}$ & 7 & \\
\hline $\begin{array}{l}0 . T 9 Y \\
\because . \mathrm{TY}\end{array}$ & $\begin{array}{l}\because 01 \\
\therefore \Delta r\end{array}$ & $\begin{array}{l}\mathrm{MN}^{\mathrm{N}} \\
\mathrm{ND}\end{array}$ & $\begin{array}{l}\because \cdots Y \\
\because \Delta y\end{array}$ & $r$ & \\
\hline \multirow[t]{2}{*}{$\begin{array}{l}\because .07 \\
\because .14 \\
\end{array}$} & $\begin{array}{l}\because 14 \\
\because 74\end{array}$ & $\begin{array}{l}\mathrm{ND} \\
\mathrm{ND}\end{array}$ & $\begin{array}{l}\because+40 \\
\because r 4\end{array}$ & سبطرةً & \\
\hline & $\begin{array}{l}\because 42 \\
\because 2\end{array}$ & $\begin{array}{l}\because \mathrm{yed} \\
\because \mathrm{r}\end{array}$ & 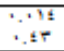 & منؤسط نُصول & \\
\hline $\begin{array}{l}\because \leqslant r \\
\because \pi r \leqslant\end{array}$ & $\begin{array}{l}\because 2 \\
\because \pi\end{array}$ & $\begin{array}{l}\because \wedge \\
\because \wedge\end{array}$ & $\begin{array}{l}\because \cdots 7 \\
\because \pi / 1\end{array}$ & , & \multirow{5}{*}{ نئه } \\
\hline $\begin{array}{l}\because 4 T \\
\because Y Y\end{array}$ & $\begin{array}{l}\because 4 \\
\because .47\end{array}$ & $\begin{array}{l}\because A x \\
\because \cdots\end{array}$ & $\begin{array}{l}\because+r 7 \\
\because r y\end{array}$ & 7 & \\
\hline $\begin{array}{l}\because+4) \\
\because \times 9\end{array}$ & $\begin{array}{l}-11 \\
1.14\end{array}$ & ND' & $\begin{array}{l}\because \cdots 9 \\
\because, 19\end{array}$ & $T$ & \\
\hline \multirow[t]{2}{*}{$\begin{array}{l}\because \cdots \\
\because .21\end{array}$} & $\because \bar{x}$ & $\because{ }^{\prime}{ }^{\prime}$ & $\begin{array}{l}\because \cdots \\
\because \because 4\end{array}$ & سبطرة & \\
\hline & $\begin{array}{l}\because r \\
\because 11\end{array}$ & $\begin{array}{l}\because \times 0 \\
\because \times 1\end{array}$ & $\begin{array}{l}\because \cdots " \\
\because \mathrm{M}\end{array}$ & لعصل & \\
\hline $\begin{array}{l}\because r t \\
\because r r\end{array}$ & 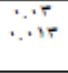 & $\begin{array}{l}\because 51 \\
\because 45\end{array}$ & $\begin{array}{l}\because 3 \\
\because 4\end{array}$ & , & \multirow{5}{*}{ تحاس } \\
\hline $\begin{array}{l}\because \leqslant Y \\
\because r e\end{array}$ & $\begin{array}{l}\because 4 \\
\because \cdots 8\end{array}$ & $\begin{array}{l}\because 81 \\
\because \mathrm{YY}\end{array}$ & $\begin{array}{l}451 \\
\because 41\end{array}$ & 7 & \\
\hline $\begin{array}{l}\because \mathrm{TA} \\
\because \mathrm{T}\end{array}$ & $\begin{array}{l}\because \wedge \\
\because \wedge\end{array}$ & ND' & $\begin{array}{l}\because \mathrm{Tr} \\
\because \mathrm{Tr}\end{array}$ & $r$ & \\
\hline \multirow[t]{2}{*}{$\therefore \cdots$} & $\begin{array}{l}\prime \\
\because \cdots\end{array}$ & ' & $\begin{array}{l}{ }^{\prime} \cdots \wedge \\
\therefore \cdots \wedge\end{array}$ & سبطرة & \\
\hline & $\begin{array}{l}\because T \\
\because 4\end{array}$ & 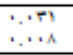 & $\begin{array}{l}\because \pi T \\
\because \pi r\end{array}$ & لعصل & \\
\hline $\begin{array}{l}r+r \\
4.3 \gamma\end{array}$ & $\begin{array}{l}\because: \\
\because 8\end{array}$ & $\begin{array}{l}\because A x \\
\because 4\end{array}$ & $\begin{array}{l}\because \pm \leqslant 4 \\
\because \leqslant 4\end{array}$ & , & \multirow{5}{*}{ تيكّل } \\
\hline 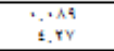 & 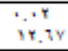 & $\begin{array}{l}\because A v \\
\because \because 4 r\end{array}$ & $\begin{array}{l}\because \therefore Y \\
\because 94 \\
\because .94\end{array}$ & 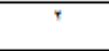 & \\
\hline ? & $\begin{array}{c}4 \\
1 \times 4 t \\
\end{array}$ & ND & $\begin{array}{l}\cdots \wedge \\
\because, n^{A}\end{array}$ & $T$ & \\
\hline $\begin{array}{l}\because \cdots \\
\because \Delta x\end{array}$ & $\begin{array}{l}01 \\
\because 44\end{array}$ & $\ddot{\mathrm{ND}}$ & 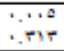 & سبطرةدة & \\
\hline & $\begin{array}{l}\because Y Y \\
4.4 Y\end{array}$ & $\begin{array}{l}\because .95 \\
\because .111\end{array}$ & $\begin{array}{l}\because \times 4 \\
\because, 14\end{array}$ & لعصل & \\
\hline
\end{tabular}

جدول (§): معامل التركيز الإحيائي ومعامل الترسيب الإحيائي للعناصر

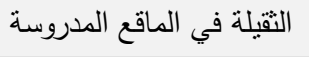

\begin{tabular}{|c|c|c|c|c|c|}
\hline \multicolumn{2}{|c|}{ بونة } & \multicolumn{2}{|c|}{ تُصب } & اتنهاك & \\
\hline$B C=$ & BSF & $\mathrm{BCF}$ & BSF & & \\
\hline Trate & T4.T & Tानाहव & $\operatorname{ling} \varepsilon$ & حثذ & \\
\hline 127.9 & $17 . .2$ & Tr.TIR & $.91 \mathrm{~V}$ & زj & \\
\hline TYYहा? & $T \cdot .11 T \varepsilon$ & $7 \pi, \varepsilon \pi T$ & $8 ., 111$ & تحسن & لختّاه \\
\hline T. & $\because,{ }^{A T / z}$ & $80 \xi \hat{\beta}$ & 98 & تصيكر & \\
\hline TFM. 1 & $0: \mathrm{Tq}^{2}$ & TV7\%? & हPOY & حذيّ & ريبي \\
\hline$\because \gamma$ & 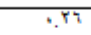 & 2.102 & 4.92 & ${ }^{2}$ & \\
\hline TY,Y & $\lambda .74 . Y$ & $T .1 .1$ & O.YY & تحأس & \\
\hline דו & $1,7 \times+1$ & .9 & $\because \wedge 94$ & تيكرل & \\
\hline $0+14.0$ & $1+4$ & 0 & $0 \& 1, \lambda$ & - بذي & صبذ \\
\hline 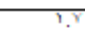 & $1 \%$ & Y.AN & 988 & ركיك & \\
\hline$r \cdot\{a\}$ & T.Yo,T & T. & אידת & نحش & \\
\hline. .69174 & $\because \cdot r^{n}$ & Y.T & $\because A R Y$ & تنيكل & \\
\hline
\end{tabular}


- Cardwell, A. J.; Hawker, D. W. and Greenway, M. (2002).Metal accumulation in aquatic macrophytes from southeast Queensland, Australia. Chemosphere, 48:653-663

- DalCorso, G. ; Farinati, S.; Maistri S. and Furini A.(2008). How plants cope with cadmium: staking all on metabolism and gene expression. J. Integr Plant Biol., 50:1268-1280.

- Das , P.; Samantaray, S. and Rout, G. R. (1998). Studies on cadmium toxicity in plants :A review . Environ, pollu., 96:29-36.

- Evans, D. and Engle, D. W. (1994). Mercury bioaccumulation in Fin Fish and Shellfish from Lavaca bay, Texes. NOVAA, Technical memorandum, : 89 .

- Faris, F. G. and Abdel Magid, I. M. (2003). Wastewater Reclamation \& Reuse in Petroleun Refinery at Algeili Area north of Kharton, J. Sci. Techno., 4:38-58.

- Hadad, H. R. ; Mufarrege, M. M. \& Pinciroli, M. (2010). Morphological Response of Typha domingensis to an Industrial Effluent Containing Heavy Metals in a Constructed Wetland. Arch Environ Contam Toxicol. Argentina, 58:666-675.

- Hegazy, A. K.; Abdel-Ghani, N.T. and El-Chaghaby G.A.(2011). Phytoremediation of industrial wastewater potentiality by Typha domingensis Int. J. Environ. Sci. Tech., 8 (3):639-648.

- Hegazy, A. K.; Abdel-Ghani, N.T. and El-Chaghaby G.A.(2011). Phytoremediation of industrial wastewater potentiality by Typha domingensis Int. J. Environ. Sci. Tech., 8 (3):639-648.

- Li, F.; Xiong, Z. and Hu, H. (2003a). Copper toxicity and accumulation in Elsholtzia splendens (in Chinese). Environ Sci., 24:30-34.

- Maine, M. A.; Suñe,' N; Hadad, H. ; Sa'nchez, G. and Bonetto, C. (2009). Influence of vegetation on the removal of heavy metals and nutrients in a constructed wetland. J Environ Manage, 90:355-363.

- Manios, T. ; Stentiford, E. and Millner, P. (2003) The effect of heavy metals accumulation on the chlorophyll concentration of Typha latifolia plants, growing in a substrate containing sewage sludge compost and watered with metaliferus water. Ecol. Eng., 20:65-74.

- Mary, G.(2008). Pigments and Moisture Contents in Phragmites australis (Cav.) Trin. Ex Steudel, Would Be Engines for Monitoring
References المصادر

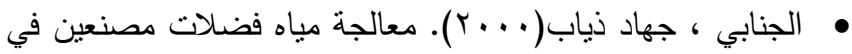

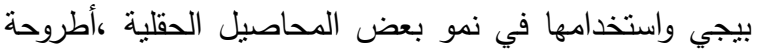
دكتوراه،كلية العلوم- جامعه الموصل .

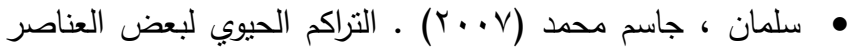
التقيلة في النبات المائي Myriophyllum demersum مجلة

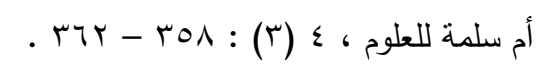

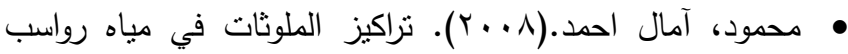

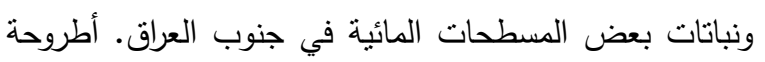
دكتوراه، كلية العلوم، جامعة البصرة ـع ؟ ك صفحة.

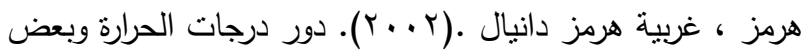

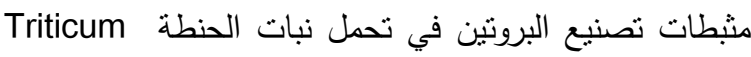

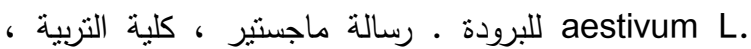

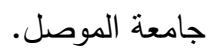

- Amakiri, J. O. (1985). Effects of oil pollution on the salt marsh grass Puecinella maritime (Huds) ph. D. Dissertation. London imperials College of Science and Technology. Cited after index to thesis, 35:1682.

- APHA (American public Helth Association). (2003). Standard methods for examination of water and wastwater, 20th, Ed. Washington DC,USA.

- Armstrong, J. and William, A. (2001). Rice and Phragmites: effects of organic acids on growth, root permeability, and radial oxygen loss to the rhizosphere1. american journal of botany.,(8): 1359-1370.

- Ayeni, O. O.; Ndakidemi, P. A.; Snyman, R.G. and Odendaal, J.P. (2010), Chemical, biological and physiological indicators of metal pollution in wetlands. Sci Res Essays, 5:1938-1949.

- Begum, A. ; Ramaiah, M. ; Khan, I. and Veena, K. (2009) . Heavy metal pollution and chemical profile of Cauvery river water. E. Journal of Chemistry , 6 (1) : 47- 52

- Bremner, J. M. and Mulvancy, C. S.(1982). Nitrogen total.:595-624.Ina.L. Page(ed.).Methods of soil analysis.Agron.No.9.part2:Chemical and microbiological properties.2nd ed. Am.Soc.Agron.Medison .WI.USA 
- Zengin, F. K. and Munzuroglu, O. (2005). Effect of Some Heavy Metals on Content of Chlorophyll,Prolin and Antioxidant Chemicals in Bean (Phaseolus vulgaris L.)Seedling .Acta Biologica Cracoviensia Series Botanica.,47:157164.
Biodegradation of Petroleum Contaminants in Constructed Wetlands. Australian Journal of Basic and Applied Sciences, 2(4): 1068-1075.

- Memon, A. R. ; Aktoprakligil, D. ; Ozdemir, A. and Vertii, A. (2000). Heavy metal accumulation and detoxification mechanisms in plants . Turk J. Bot. , 25 : 111- 1 Chugh, L. K, and Sawhney S. K. (1999). Photosynthetic activities of Pisum sativum seedlings grown in presence of cadmium. Plant Physiol. Biochem.,37:297-303.

- Mesmar, M. N., and Jaber, K. (1991). The toxic effect of lead on seed germination, growth, chlorophyll and protein contents of wheat and Lens. ACTA . Biol . Hung .,42(4) : 331-344.

- Myśliwa-Kurdziel B.; Prasad, M. N. V. and Strzałka, K. (2004). Photosynthesis in heavy metal stressed plants. In: Prasad MNV(ed)Heavy metal stress in plants from biomolecules to ecosystems, 2nd edn. Springer, Berlin, : 462-470,

- Ololade, I. A. and Ologundudu, A. (2007).Concentration and bioavailability of cadmium by some plants. African Journal of Biotechnology.,6(16):1916-1921.

- Sarma, H.(2011).Metal hyperaccumulation in plants: a review focusing on phytoremediation technology. J Environ. Sci. Technol., 4:118138.

-Shukla, O. P.; Dubey, S. and Rai, U. N. (2010). Preferential accumulation of cadmium \& chromium: Toxicity in Bacopa monnieri L. under mixed metal treatments. B Environ Contam Toxicol., :252-257.

- Vassilev, A. and Yordanov, I. (1997). Reductive analysis of factors limiitinc growth of cadmium-treated plants: A review .J Bulg plant physiol., :114-133.

- Vassilev, A.(2003). Physiological and agro ecological aspects of cadmium interactions with Barley plants : Anov review .J Central European Agriculture . 4(1):65-75.

- Ying Ma,(2005). Monitoring of Heavy Metals in the Bottelary River Using Typha capensis and Phragmites australis. Department of Biodiversity and Conservation Biology, University of the Western Cape

- Yruela, I. (2009). Copper in plants: acquisition, transport and interactions. Funct Plant Biol., 36: 409-430. 